\title{
Particle formation at a continental background site: comparison of model results with observations
}

\author{
U. Uhrner ${ }^{1}$, W. Birmili ${ }^{2}$, F. Stratmann ${ }^{3}$, M. Wilck ${ }^{3}$, I. J. Ackermann ${ }^{4}$, and H. Berresheim ${ }^{5}$ \\ ${ }^{1}$ Institute for Tropospheric Research, Permoserstr. 15, 04318 Leipzig, Germany \\ ${ }^{2}$ Division of Environmental Health and Risk Management, Birmingham University, B15 2TT, UK \\ ${ }^{3}$ Institute for Tropospheric Research, Permoserstr. 15, 04318 Leipzig, Germany \\ ${ }^{4}$ Ford Research Centre Aachen, Süsterfeldstr. 200, 52072 Aachen, Germany \\ ${ }^{5}$ German Weather Service - Deutscher Wetterdienst, Meteorological Observatory Hohenpeissenberg, Albin-Schwaiger-Weg \\ 10, 83282 Hohenpeissenberg, Germany
}

Received: 18 October 2002 - Published in Atmos. Chem. Phys. Discuss.: 16 December 2002

Revised: 4 March 2003 - Accepted: 11 March 2003 - Published: 31 March 2003

\begin{abstract}
At Hohenpeissenberg $\left(47^{\circ} 48^{\prime} \mathrm{N}, 11^{\circ} 07^{\prime} \mathrm{E}, 988 \mathrm{~m}\right.$ asl), a rural site 200-300 m higher than the surrounding terrain, sulphuric acid concentrations, particle size distributions, and other trace gas concentrations were measured over a two and a half year period. Measured particle number concentrations and inferred particle surface area concentrations were compared with box-model simulations for 12 carefully selected data sets collected during the HAFEX experiment (Birmili et al., 2003). The 12 cases were selected after meteorological and aerosol dynamical criteria in order to justify the use of a box-model. The aerosol model included a binary sulphuric acid water nucleation scheme. Calculated nucleation rates were corrected with a factor to match measured and calculated particle number concentrations. For the investigated 12 data sets, the correction factors were smallest for measurements made under stable thermal stratification and low wind conditions, i.e. conditions that are frequently encountered during winter. Correction factors were largest for measurements made under strong convective conditions.

Our comparison of measured and simulated particle size distributions suggests that the particle formation process maybe strongly influenced by mixing processes driven by thermal convection and/or wind sheer.
\end{abstract}

\section{Introduction}

Aerosols impact climate (e.g. Charlson and Heintzenberg, 1995) and human health (e.g. Dockery and Pope, 1994). New particle formation from gas-phase precursors, i.e. nucleation, is frequently observed in marine locations (e.g. Weber et al., 1999; O'Dowd et al., 2002) and in continental locations, such as forests (Mäkelä et al., 1997), remote

Correspondence to: U. Uhrner (uhrner@tropos.de) (e.g. Weber et al., 1997) and polluted sites (e.g. Birmili and Wiedensohler, 2000; McMurry et al., 2000). However, the fundamental processes that cause nucleation and subsequent growth in the size-range of a few nanometers are still uncertain.

Sulphuric acid and water are believed to be the important constituents controlling atmospheric nucleation processes. Calculated nucleation rates using classical binary $\mathrm{H}_{2} \mathrm{SO}_{4}$ $\mathrm{H}_{2} \mathrm{O}$ theory substantially underestimate the observed nucleation rates for mid-latitude ambient conditions (e.g. Weber et al., 1998; O'Dowd et al., 1999). Observed $\mathrm{H}_{2} \mathrm{SO}_{4}$ concentrations are about 1 order of magnitude too low to explain the ambient formation according to classical binary theory.

More complex nucleation mechanisms have been proposed, such as ion-mediated nucleation and growth (Yu and Turco, 2000) and the participation of a third molecule such as ammonia $\left(\mathrm{NH}_{3}\right)$ (Coffman and Hegg, 1995; Korhonen et al., 1999), or the ubiquitous existence of thermodynamically stable $1-3 \mathrm{~nm}$ clusters probably formed by nucleation of $\mathrm{H}_{2} \mathrm{SO}_{4}, \mathrm{H}_{2} \mathrm{O}$, and $\mathrm{NH}_{3}$ (Kulmala et al., 2000). In comparison to binary systems, for ternary nucleation of $\mathrm{H}_{2} \mathrm{SO}_{4}$, $\mathrm{H}_{2} \mathrm{O}$, and $\mathrm{NH}_{3}$, up to 2 orders of magnitude less gas-phase $\mathrm{H}_{2} \mathrm{SO}_{4}(\mathrm{~g})$ is needed to achieve observed nucleation rates. However, the observed growth in the nanometer range can not be attributed to the subsequent condensation of $\mathrm{H}_{2} \mathrm{SO}_{4}$, $\mathrm{H}_{2} \mathrm{O}$, and $\mathrm{NH}_{3}$. Therefore, to explain observed condensational growth rates, additional unknown species must participate in subsequent growth (Kulmala et al., 2000).

Other researchers noted that favourable atmospheric conditions, such as turbulence due to breaking Kelvin-Helmholtz waves (Bigg, 1997) or boundary layer mixing processes (Easter and Peters, 1994; Nilsson and Kulmala, 1998), and atmospheric waves (Nilsson et al., 2000) can enhance nucleation rates by up to several orders of magnitude. Weber

(C) European Geosciences Union 2003 
et al. (1999) suggested that nucleation mechanisms may vary with altitude. By comparing observed new-particle formation rates against modelled nucleation rates using classical binary nucleation, they concluded that at least for higher elevations in remote marine regions, new particles can be formed along cloud perimeters through $\mathrm{H}_{2} \mathrm{SO}_{4}-\mathrm{H}_{2} \mathrm{O}$ nucleation.

This work focuses on the impact of meteorological conditions on new particle formation and aerosol dynamics. Data sets consisting of $\mathrm{H}_{2} \mathrm{SO}_{4(\mathrm{~g})}$, $\mathrm{RH}, \mathrm{T}$, and particle size distributions collected during the HAFEX (Hohenpeissenberg Aerosol Formation Experiment) campaign (Birmili et al., 2003) were used as direct input for aerosol dynamics simulations which included particle nucleation and growth due to condensation and coagulation for the binary $\mathrm{H}_{2} \mathrm{SO}_{4}-\mathrm{H}_{2} \mathrm{O}$ system. Instead of using computed $\mathrm{H}_{2} \mathrm{SO}_{4}(\mathrm{~g})$ concentrations, measured time series of $\mathrm{H}_{2} \mathrm{SO}_{4}(\mathrm{~g})$ were used as direct model input. Similar to many other studies, only ground-based measurements were available. Because a simple box-model approach was used, no spatial distributions of precursors or aerosol properties were needed to initialise the simulations. Uncertainties of $\mathrm{H}_{2} \mathrm{SO}_{4}(\mathrm{~g})$ concentrations used in the model were reduced to measurement errors.

The goal of this work was to relate differences between measured and modelled particle number concentrations to the occurrence of processes such as vertical exchange and small-scale turbulence and transport. To achieve this, the differences between measured and modelled particle number concentrations were quantified in terms of a correction factor applied to the modelled nucleation rate. The correction factor was varied in the way that the differences between measured and modelled particle number concentrations were minimised. The determined correction factors were then related to measured physical parameters such as the nearsurface temperature gradient, wind speed, trace gas concentrations, humidity and temperature profiles from which the occurrence of processes like vertical exchange, small-scale turbulence and transport can be inferred. From the 46 available data sets classified as Type "I" or "II" (strong or medium events), 12 data sets were chosen which met meteorological and aerosol dynamical criteria which justified the application of a box-model.

As aerosol dynamical model, a box model version of the lognormal MADMAcS model (Multicomponent Aerosol Dynamics Modal Approach System) (Wilck and Stratmann, 1997; Wilck, 1998) was used. In this model, regarding particle nucleation and condensational growth, the binary $\mathrm{H}_{2} \mathrm{SO}_{4}$ $\mathrm{H}_{2} \mathrm{O}$ system was applied. The more elaborate ternary, i.e. the $\mathrm{H}_{2} \mathrm{SO}_{4}-\mathrm{H}_{2} \mathrm{O}-\mathrm{NH}_{3}$, system was not considered because of the following severe disadvantages:

- It is reported that the ternary nucleation scheme generates large numbers of nuclei below the detectable minimum size. Kulmala et al. (2000) stated that in order to grow these particles into the detectable size range, other yet unidentified vapours " $X_{i(g)}$ " then $\mathrm{H}_{2} \mathrm{SO}_{4(\mathrm{~g})}$ are required.

- As $\mathrm{NH}_{3}$ concentrations were not measured during HAFEX, usage of a ternary nucleation parametrisation would imply the assumption of particular $\mathrm{NH}_{3}$ concentations, i.e. another additional and undesired free parameter.

- To make nucleation and growth consistent, the effects of $\mathrm{NH}_{3}$ and substances " $X_{i(g)}$ " on particle growth have to be accounted for.

\section{Field measurement data used for comparison}

We give a brief description of the measured data that we used for comparison with the simulation results. More detailed information about the HAFEX measurements (1998-2000) can be found in Birmili et al. (2003) and in the case study by Birmili et al. (2000). For this comparison we used data from the Meteorological Observatory at Hohenpeissenberg (MOHp) located in South Germany, which is run by the German Weather Service (DWD). Measurements were made on top of the Hohenpeissenberg (988 m), a single hill 200-300 $\mathrm{m}$ higher than the surrounding terrain. This remote site is located $60 \mathrm{~km}$ southwest of Munich and 30-40 km north of the Bavarian Alps.

Available long-term measurement data used in this work included dry, submicrometer particle size distributions ranging from 3-700 $\mathrm{nm}$ measured with a differential mobility particle sizer, gas-phase $\mathrm{H}_{2} \mathrm{SO}_{4}$ concentrations measured by using atmospheric-pressure chemical ionisation mass spectronomy (AP/CIMS, see Berresheim et al., 2000, for details), $\mathrm{NO}_{\mathrm{x}}$, and routinely measured meteorological data. Ammonia measurements were not made. The time resolution was 15 min for the meteorological data and 5 min for the $\mathrm{H}_{2} \mathrm{SO}_{4(\mathrm{~g})}$ data. Size distributions were measured every $15 \mathrm{~min}$. A CIMS measurement cycle consisted of $\mathrm{H}_{2} \mathrm{SO}_{4(\mathrm{~g})}$ and $\mathrm{OH}$ concentration measurements. Therefore, there are gaps of several minutes in the data for $\mathrm{H}_{2} \mathrm{SO}_{4(\mathrm{~g})}$, when $\mathrm{OH}$ concentrations were measured. Interpolated values for $\mathrm{H}_{2} \mathrm{SO}_{4}(\mathrm{~g})$ were used for those periods. Hourly averaged $\mathrm{NO}_{\mathrm{x}}$ data were used for interpretation of our results for particle growth.

Local characteristics that must be considered in the interpretation of the data are inhomogeneities in heat flux, temperature, humidity, and local wind systems originating from the position of the site. The site is affected by lee effects due to southerly airflows, in particular with foehn. Mountain winds can evolve particularly in summer due to intense irradiation onto the southern slopes of the Bavarian Alps, which creates a mesoscale circulation system that causes a compensating sinking air motion and northerly winds at the Hohenpeissenberg site (Fricke et al., 1997). Consequently, there is a local air mass change due to changes in the local flow pattern. 


\section{Modelling and comparison methodology}

One of the goals of this study was to identify the atmospheric processes that control particle formation and growth. For the meteorological conditions corresponding to the measured data we used to compare with our simulation results, the following new-particle formation scenarios are possible:

- Particle nucleation occurs inside the boundary layer, where particle precursor concentrations are high. $\mathrm{Nu}-$ cleation is controlled by gas-phase chemical reactions (source of condensable material) and existing particles, which act as condensational sink (e.g. Pirjola et al., 1999).

- Particle nucleation occurs near inversion layers and new particles are mixed downward during the break-up of the inversion layer. Turbulent transport may control new-particle formation by (a) initiating nucleation by mixing air parcels with different chemical and thermodynamical properties (Nilsson and Kulmala, 1998; Jaenisch et al., 1998) and by (b) mixing newly formed particles down to the ground, where they can be detected.

Depending on the meteorological conditions, both scenarios are possible. Based on only point measurements of the particle size distribution and measurement of only a limited number of particle precursors, it is not possible to determine which of these scenarios dominated particle nucleation in the measured data sets. However, by combining measured size distribution and particle precursor data, known meteorological conditions at the time of such measurements, and by using a suitable aerosol dynamics model, it is possible to determine which of the particle nucleation scenarios was dominant. Therefore, based on the experimental data available from the HAFEX experiments, we used a box model to simulate particle nucleation and the development of the particle size distribution. The model is initialised by using measured particle size distributions at the start of each model run and the particle dynamics are driven by measured temperatures, relative humidities, and $\mathrm{H}_{2} \mathrm{SO}_{4}$ (g) concentrations. Simulating carefully selected particle nucleation events and relating the differences between measured and calculated particle size distributions to suitable meteorological parameters, the nearsurface temperature gradient and the local Richardson number can be used to indicate where nucleation occurs.

Using a box model is sufficient because the data was measured at a single point and is therefore 0-dimensional. Furthermore, multidimensional simulations would involve unknown boundary conditions, such as the 3-D distribution of particle size distribution, gaseous precursor type, and emission rates, which would introduce an undesirable number of free parameters in the model.

\subsection{Aerosol dynamics model}

The simulations were made with a box model version of the lognormal MADMAcS model (Multicomponent Aerosol Dynamics Modal Approach System) (Wilck and Stratmann, 1997; Wilck, 1998). The model accounts for nucleation, condensation, and coagulation. Atmospheric mixing, sedimentation, and deposition were not considered. Nucleation rates were calculated by using the binary nucleation theory for the $\mathrm{H}_{2} \mathrm{SO}_{4}-\mathrm{H}_{2} \mathrm{O}$ system (Kulmala et al., 1998). The nucleation rate, $J\left[\# /\left(m^{3} s\right)\right]$ can be expressed as

$J=F_{\text {nuc }} \exp \left(-\frac{\Delta G^{*}}{k_{b} T}\right)$

where $k_{b}$ is the Boltzmann constant, $T$ is temperature, and $\Delta G^{*}$ is the energy required to form a cluster sufficiently large that it will not reevaporate (critical cluster). The kinetic pre-exponential factor, $F_{n u c}$, expresses the rate at which vapour is transported to critical clusters. A detailed description of the formulation of $F_{n u c}$ and $\Delta G^{*}$ is given in Kulmala et al. (1998). The critical cluster composition according to Wilemski (1984) is solved numerically and the hydrate interaction (Jaecker-Voirol et al., 1987) is taken into account. The water content of the clusters and particles is computed from an equilibrium relationship with the relative humidity. Prognostic variables are "dry" particle size distribution moments, $M_{k, j}$, representing particle number concentration $(k=0)$, surface area $(k=2)$, and mass $(k=3)$ for each mode $j$. $M_{k, j}$ can be expressed as

$M_{k, j}(t)=N_{j} \int_{0}^{\infty} \tilde{m}_{p, j}^{k} f_{\ln j} \mathrm{~d} \tilde{m}_{p, j}$

$f_{\ln _{j}}=\frac{1}{\sqrt{2 \pi} \tilde{m}_{p, j} \ln \sigma_{g, j}} \exp \left(-\frac{\ln ^{2}\left(\tilde{m}_{p, j} / \tilde{m}_{g N, j}\right)}{2 \ln ^{2} \sigma_{g, j}}\right)$

where $f_{\ln j}$ represents the normalized lognormal frequency function of mode $j, \tilde{m}_{p}$ is the "dry" particle mass, $\tilde{m}_{g N}$ is the "dry" geometric mean particle mass of the number-weighted distribution, and $\sigma_{g}$ is the geometric standard deviation. The time evolution of the particle size distribution can be described by the time evolution of the moments of the "dry" distribution as

$$
\begin{aligned}
& \frac{\partial M_{k, j}}{\partial t}=\delta_{j_{n u c}, 1}\left(\tilde{m}_{p}^{*}\right)^{k} J \\
& +k N_{j} \int_{0}^{\infty} \tilde{m}_{p}^{k-1}\left[C\left(m_{p, j}\right)-E\left(m_{p, j}\right)\right] f_{j}^{\ln }\left(\tilde{m}_{p}\right) \mathrm{d} \tilde{m}_{p} \\
& -\sum_{i=1}^{n_{m}} N_{j} N_{i} \int_{0}^{\infty} \int_{0}^{\infty} \tilde{m}_{p}^{k} \beta\left(m_{p}, m_{p}^{\prime}\right) f_{j}^{\ln }\left(\tilde{m}_{p}\right) f_{i}^{\ln }\left(\tilde{m}_{p}^{\prime}\right) \mathrm{d} \tilde{m}_{p}^{\prime} \mathrm{d} \tilde{m}_{p} \\
& \quad+\sum_{i, v=1}^{n_{m}} C_{i v j} N_{i} N_{v} \\
& \cdot \int_{0}^{\infty} \int_{0}^{\infty}\left(\tilde{m}_{p}+\tilde{m}_{p}^{\prime}\right)^{k} \beta\left(m_{p}^{\prime}, m_{p}\right) f_{i}^{\ln }\left(\tilde{m}_{p}\right) f_{v}^{\ln }\left(\tilde{m}_{p}^{\prime}\right) \mathrm{d} \tilde{m}_{p}^{\prime} \mathrm{d} \tilde{m}_{p}
\end{aligned}
$$

Atmos. Chem. Phys., 3, 347-359, 2003 
where $N_{j}$ represents the total number concentration in mode $j, C\left(m_{p}\right)$ and $E\left(m_{p}\right)$ represent the condensation and evaporation rates, respectively, and $\beta\left(m_{p}, m_{p}^{\prime}\right)$ represents the coagulation coefficient for particles of mass $m_{p}$ and $m_{p}^{\prime}$. The tensor $C_{i v j}$ expresses the coagulation convention for the coagulation gain term as suggested by Whitby and McMurry (1997). $\quad C_{i v j}=1 / 2$ if $i=v=$ $j$ (intramodal coagulation), $C_{i v j}=1$ if $i=j$ and $d_{g N i}>$ $d_{g N v}, \quad C_{i v j}=1$ if $v=j$ and $d_{g N i} \leq d_{g N v}$, and $C_{i v j}=$ 0 otherwise. The integrals must be evaluated numerically because they involve a nonlinear dependence of the "wet" particle mass $m_{p}$ on the "dry" particle mass $\tilde{m}_{p}$. The numerical integrals were evaluated with an 8-point Gauss-Hermite quadrature technique.

Up to four modes were used. The model was initialised by using modal parameters for particle number concentration $N$, geometric mean diameter $\mathrm{d}_{\mathrm{gN}}$, and standard deviation $\sigma$ for each mode; $\mathrm{H}_{2} \mathrm{SO}_{4(\mathrm{~g})}$, $\mathrm{RH}$, and temperature. The measured time series of $\mathrm{H}_{2} \mathrm{SO}_{4}(\mathrm{~g}), \mathrm{RH}$, and temperature were used as the thermodynamic forcing parameters.

\subsection{Data selection}

In order to compare modelled results against measured results the appropriate use of a box model has to be justified. Consequently due to the underlying assumption of horizontal homogeneous conditions suitable cases must be carefully selected in order to exclude strong effects of wind veering and inhomogeneities due to the terrain on aerosol dynamical processes. In the companion article (Birmili et al., 2003) 46 data sets were classified as Type "I" or "II" (strong and medium events) and comprised only a small fraction of the HAFEX campaign (1998-2000). This classification was purely based on the particle number concentration for particles sized between 3 and $11 \mathrm{~nm}$. From these 46 data sets, cases were selected that matched the following criteria:

- Data sets with strong veering of the wind prior to and during nucleation were rejected, because local wind systems such as upslope flows or mountain wind systems involve varying transport patterns and air mass changes. Therefore, data sets were chosen with either constant wind direction at wind speeds $>4 \mathrm{~m} / \mathrm{s}$ or data sets with moderate changes $\left(<90^{\circ}\right)$ in wind direction for wind speeds $<4 \mathrm{~m} / \mathrm{s}$ prior to and during particle nucleation.

- Because the site is in close proximity to the Alps, which reach an elevation of $2961 \mathrm{~m}$ to the south, data sets influenced by foehn conditions were rejected, such as data sets with strong winds from the southeast-southwest sector, low relative humidities, and relatively high temperatures.
- Smooth time evolution of $d_{\mathrm{gN}}$ for the nucleation mode (consisting of the smallest particles in the size distribution, ranging from $3-11 \mathrm{~nm}$ ).

- A significant particle number concentration of particles smaller than $11 \mathrm{~nm}$.

- availability of simultaneously measured temperature, humidity, $\mathrm{H} 2 \mathrm{SO} 4(\mathrm{~g})$, wind and size distribution data in the period of interest.

12 data sets met these criteria, and these are summarized in Table 1.

3.3 Comparison of measured and simulated particle size distributions

The simulated and measured particle size distributions were compared. To avoid artifacts due to the data-reduction procedure (e.g. fitting lognormal distributions to measured size distributions) and to reduce the influence of model assumptions such as the multi-modal lognormal size distributions used in MADMAcS, the integral moments of the measured and simulated particle size distributions were compared. The moments we compared were total number and surface area concentrations. Because the simulated particle size distributions start at the size of the critical cluster size of about $1 \mathrm{~nm}$ and because the measured particle size distributions start at the lower detection limit of the measurement instruments which was about $3 \mathrm{~nm}$, the simulated particle size distribution moments for the nucleation mode were integrated from $3 \mathrm{~nm}$ upwards:

$M_{k, 1}=\int_{3 n m}^{\infty} \tilde{d}_{p}^{k} n_{1}\left(\tilde{d}_{p}\right) \mathrm{d} \tilde{d}_{p}$

where $n_{1}$ represents the lognormal size distribution of mode $j=1$ and $\tilde{d}_{p}$ represents the dry particle diameter.

This integration limit affects only the zeroth and first moment when nucleation occurs, and the impact on higher moments is negligible. The zeroth moment that represents the corrected particle number concentration is therefore represented by $\mathrm{N}_{>3 \mathrm{~nm}}$. To determine from the experimental data which of the two nucleation scenarios were active, the difference between the measured and modelled evolution of the size distribution moments was evaluated. As an indicator for these differences related to particle number concentration, a linear correction factor for the nucleation rate, $c f$, is defined as

$J_{c}=c f \cdot J$

$c f$ is the only free parameter in the model and was determined iteratively by varying $c f$ until the measured and simulated peak number concentrations matched within $\pm 25 \%$. The result of this procedure is shown in Fig. 1 for data taken on 19 May 1998 and 26 January 2000. Figure 1 shows measured and simulated total particle number concentration as a function of time for two values of $c f$ for each data set. 

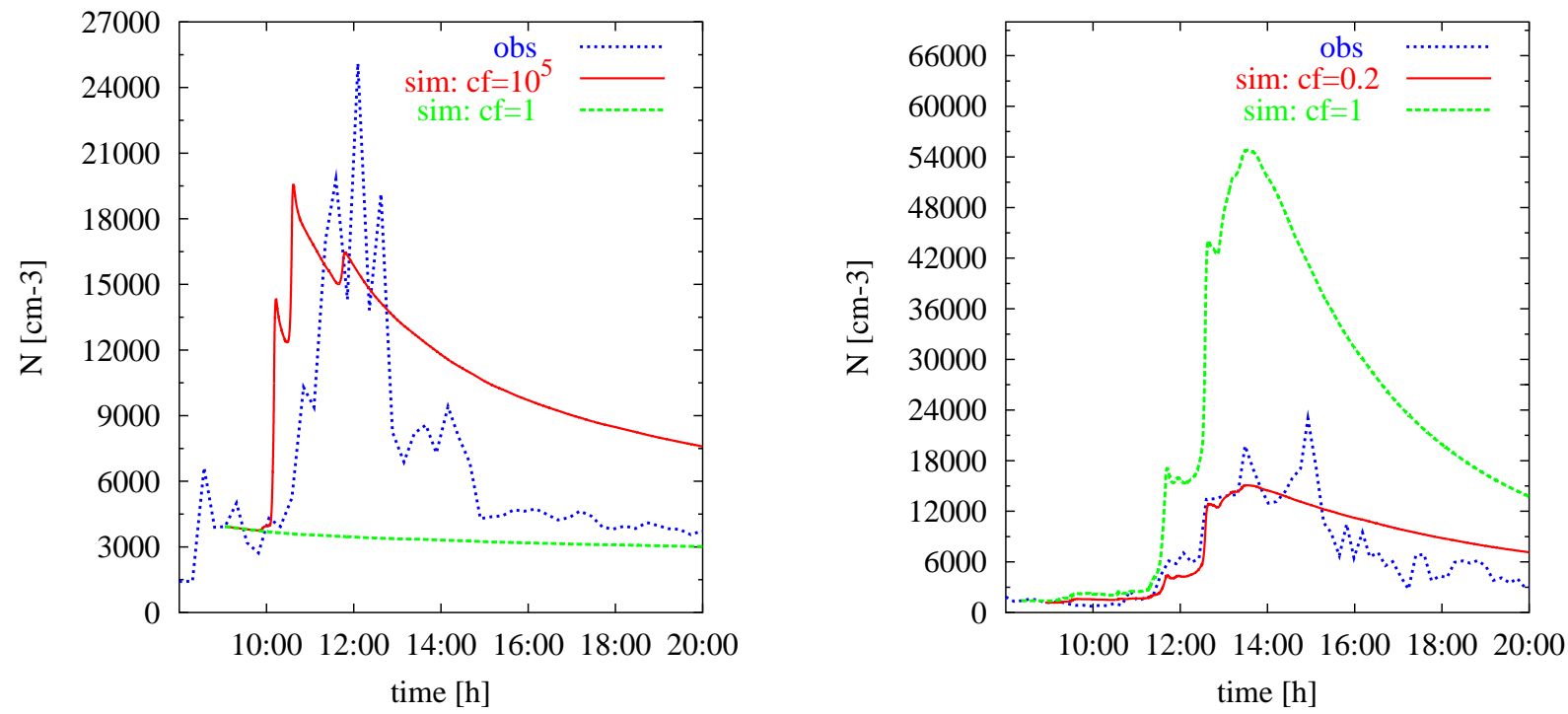

Fig. 1. Effect of $c f$ on the simulated particle formation rates for 19 May 1998 (left, $c f=10^{5}$ ) and 26 January 2000 (right $c f=0.2$ ).

Figure 1 indicates that different values of $c f$ were required to match particle number concentration for each of the data sets. For 19 May $1998 c f=10^{5}$, and for 26 January 2000 $c f=0.2$.

The data sets we used for comparison exclude strong effects of local air masses affected by veering winds. However, days with clear-sky radiation exhibited a smooth, continuous evolution in temperature, humidity, particle number concentration, particle diameter, and other parameters, indicating that they were affected by vertical exchange and turbulent transport processes. These processes, which could not be accounted for in our box-model, may increase nucleation rates (see Easter and Peters, 1994; Nilsson and Kulmala 1998), requiring a high value of $c f$ to achieve acceptable comparison between measured and simulated particle concentrations.

This suggests the use of regression analysis to relate the correction factor to meteorological properties such as the near-surface temperature gradient and the bulk Richardson number, $R i_{B}$. These parameters are related to the meteorological conditions controlling new-particle formation and may indicate which nucleation scenario was active.

The model was initialised $2-4 \mathrm{~h}$ before the observed increase in particle number concentration, at times where fluctuations in particle surface area concentration were less pronounced and therefore represented the background aerosol before nucleation occurred ${ }^{1}$. For data sets that displayed

\footnotetext{
${ }^{1} 20$ April 1998 featured a preceding ancillary maxima (9000 $\left.\# /\left(\mathrm{cm}^{3}\right)\right)$. Therefore, the model was initialised after the first particle number increase at a value corresponding to the minimum in particle number concentration 1-1 1/2 hours before the second increase
}

strong fluctuations in particle surface area concentration the model was initialised at times where the particle surface area concentration was at approximately the mean value (e.g. see Fig. 2p for 19 May 1998).

The input for the aerosol dynamics model were determined from the measured particle size distributions by using a leastsquares fit for 2-4 modes, and yielded lognormal fit parameters $N, \mathrm{~d}_{\mathrm{gn}}$ and $\sigma$. For details on this fitting procedure, see Birmili et al. (2001).

\section{Results}

To illustrate the different types of aerosol dynamics observed during HAFEX, four data sets with different characteristic temperature, humidity, $\mathrm{H}_{2} \mathrm{SO}_{4(\mathrm{~g})}$, particle number concentration, and particle surface area concentration were chosen. Then differences between measured and simulated results were related by using regression analysis to additional meteorological information, such as near-surface temperature gradients and wind speed.

\subsection{Four data sets selected for detailed comparison}

Of the four data sets we selected for case studies, two were in winter and two were in spring. The measured time series of $\mathrm{T}$ and $\mathrm{RH}$ for these data sets are shown in Figs. $2 \mathrm{a}-\mathrm{d}$, for $\mathrm{H}_{2} \mathrm{SO}_{4(\mathrm{~g})}$ in Fig. 2e-h. In the lower panels of Fig. 2 the measured number concentration (Figs. 2i-1) and particle surface area concentration (Fig. $2 \mathrm{~m}-\mathrm{p}$ ) are shown for 26 December 1998, 26 January 2000, 20 April 1998, and 19 May 1998. 
a)

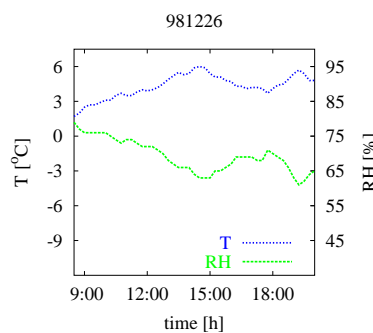

e)

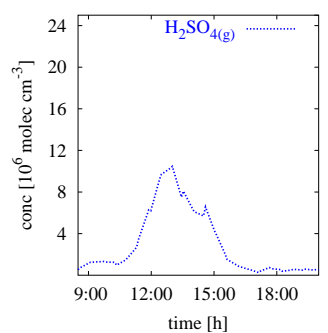

i)

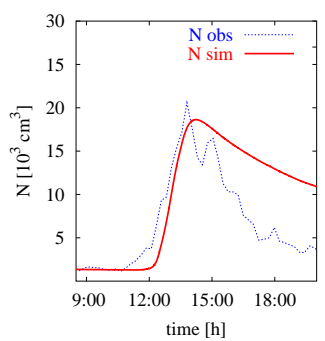

m)

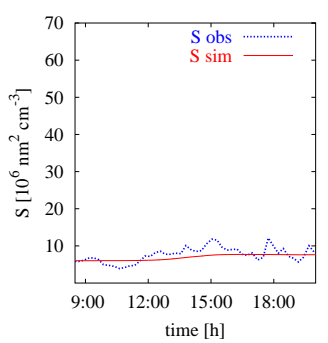

b)

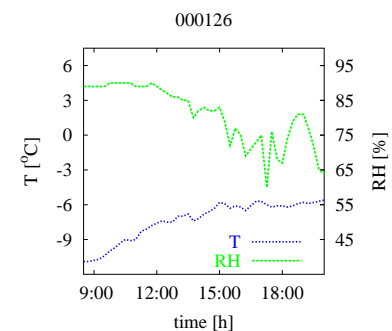

f)

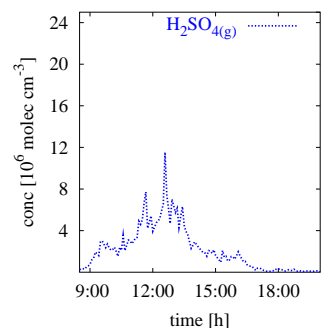

j)

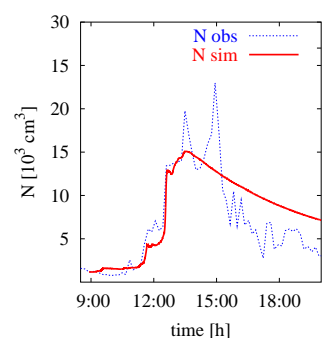

n)

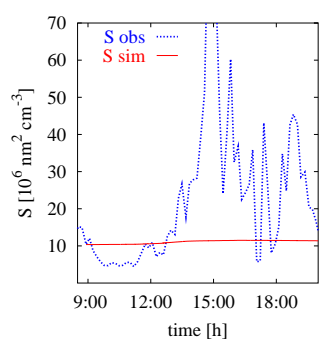

c)

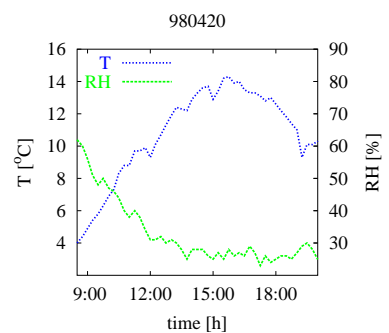

g)

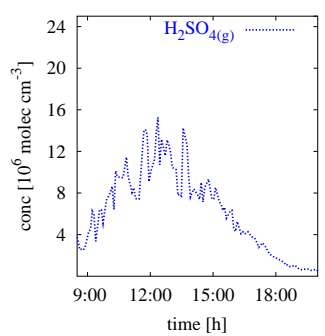

$\mathrm{k})$

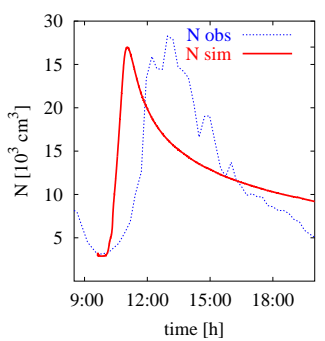

o)

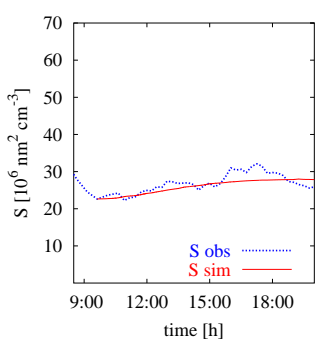

d)

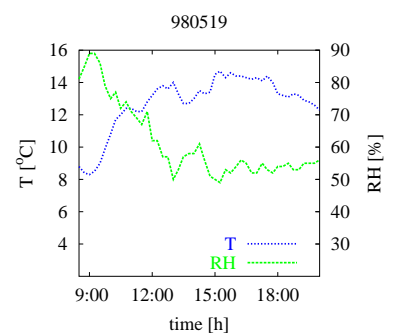

h)

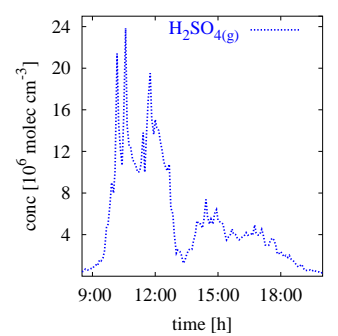

1)

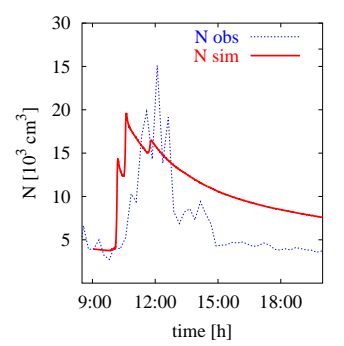

p)

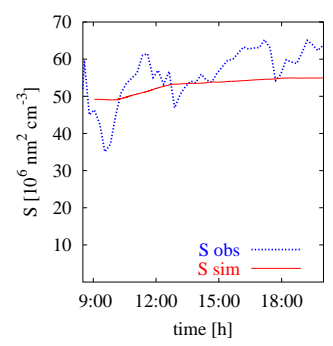

Fig. 2. Data sets (from left to right) for 26 December 1998, 26 January 2000, 20 April 1998, and 19 May 1998 (each panel). The panels show measured surface temperature and relative humidity (a-d), measured $\mathrm{H}_{2} \mathrm{SO}_{4}(\mathrm{~g})(\mathbf{e}-\mathbf{h})$, measured and simulated time evolution of $\mathrm{N}_{>} 3 \mathrm{~nm}$ (i-l), and measured and simulated time evolution of particle surface area concentration (m-p).

26 December 1998 and 26 January 2000: Both winter cases are characterised by low temperatures, stable stratification, relatively high relative humidities, and southwesterly winds prior to nucleation. On 26 December 1998 there were occasional clouds, sustained winds from the southwest, and a near-surface temperature gradient of about $0.3 \mathrm{Km}^{-1}$ prior to increasing particle number concentration and about $0.7 \mathrm{Km}^{-1}$ in the afternoon. 26 January 2000 had low, but variable local winds during and after particle nucleation, a near-surface temperature gradient of about $0.6-1.2 \mathrm{Km}^{-1}$ prior to the main particle number increase, and neutral shortly after the first maximum occurred in $\mathrm{N}_{>3} \mathrm{~nm}$. In par- ticular, for winter cases, the measured $\mathrm{N}_{>3} \mathrm{~nm}$ resembles the evolution of $\mathrm{H}_{2} \mathrm{SO}_{4}(\mathrm{~g})$ with a time lag of about 1-2 h.

20 April 1998 and 19 May 1998: For 20 April 1998 typical diurnal cycles for $\mathrm{T}$ and $\mathrm{RH}$ for a day with strong solar radiation were measured. Winds were low and predominantly from southerly directions. On this day two different maxima in $\mathrm{N}_{>3} \mathrm{~nm}$ were observed, a relatively weak maximum at 08:00 and the main peak between 12:00-13:00.

On 19 May 1998 there were scattered clouds and highly variable $\mathrm{H}_{2} \mathrm{SO}_{4}$ concentrations. However, $\mathrm{T}$ and $\mathrm{RH}$ displayed values typical of a day with strong solar radiation. The winds were low and variable. Both spring days were characterised 

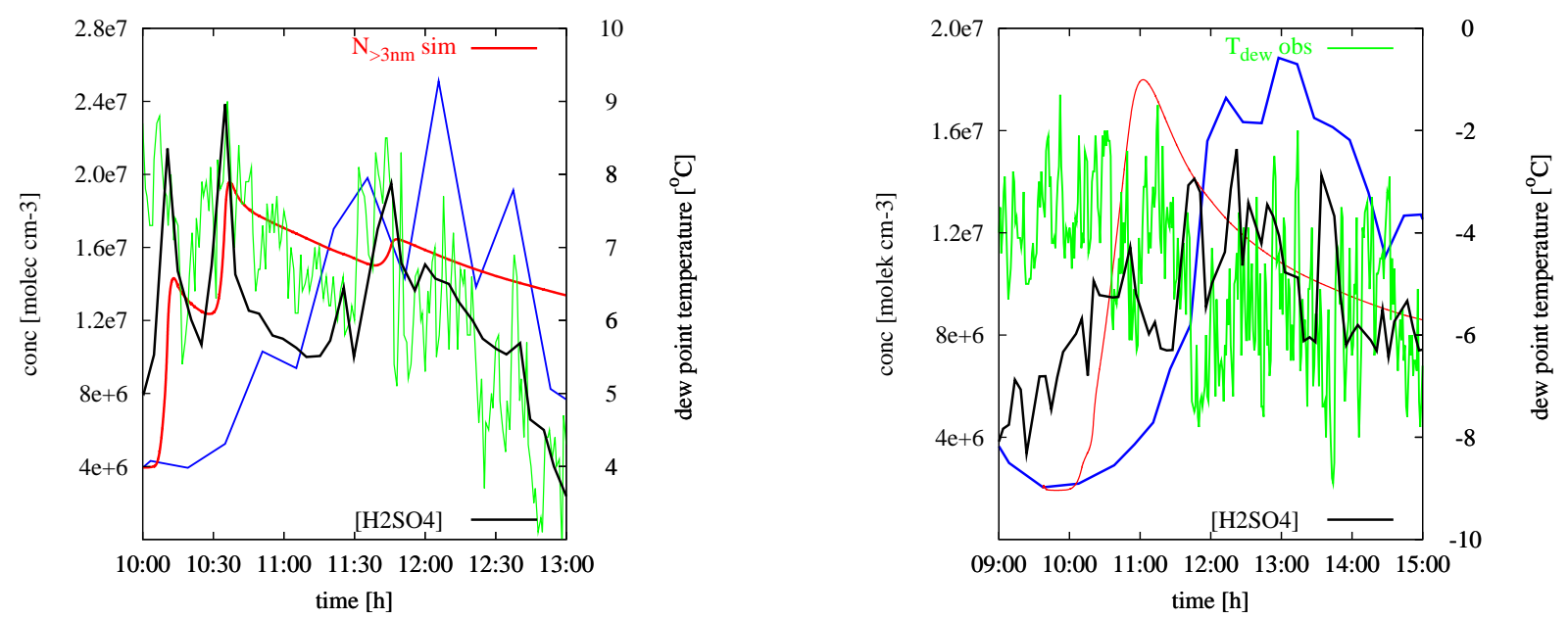

Fig. 3. Dew-point temperature taken at 1-min intervals and $\mathrm{H}_{2} \mathrm{SO}_{4(\mathrm{~g})}$ concentrations measured at MOHp, 19 May 1998 (left) and 20 April 1998 (right). $\mathrm{N}_{\mathrm{obs}}$ is indicated in green and $\mathrm{N}_{>} 3 \mathrm{~nm}$ is indicated in red.

by convective conditions. On both days there was a strong, negative near-surface temperature gradient up to $-4 \mathrm{Km}^{-1}$ at the measurement site, and the profiles for temperature and specific humidity indicated well-mixed boundary layers reaching up to $1700 \mathrm{~m}$ (see Fig. 4).

On 19 May and 26 January the increases in $\mathrm{H}_{2} \mathrm{SO}_{4}(\mathrm{~g})$ and $\mathrm{N}_{>3 \mathrm{~nm}}$ were rapid, in contrast to 20 April and 26 December for which $\mathrm{H}_{2} \mathrm{SO}_{4}(\mathrm{~g})$ and $\mathrm{N}_{>} 3 \mathrm{~nm}$ showed smooth changes and one major increase in particle number concentration occurred (Figs. 2e-1).

Figure 2 indicates that an increase of $\mathrm{N}_{>3} \mathrm{~nm}$ is accompanied by a drop in relative humidity, especially preceding an increase in $\mathrm{H}_{2} \mathrm{SO}_{4}(\mathrm{~g})$ concentration and preceding a minimum in particle surface area concentration. The time series for surface temperature are dominated by the diurnal cycle and all four data sets exhibit only minor changes prior to the observed nucleation burst.

The two lower panels of Fig. 2 show simulated results (solid red lines) as well as measured results (dashed blue lines) for particle number concentration (Figs. 2i-1) and particle surface area concentration (Figs. 2m-p). The increase in $\mathrm{N}_{>3 \mathrm{~nm}}$ is reproduced well for 26 December 1998, which is characterised by $\mathrm{N}_{>3 \mathrm{~nm}}$ increasing continuously over a two-hour period (Fig. 2i). The onset of nucleation was well predicted.

For 26 January 2000, the simulation reproduces the distinct increases of the measured $\mathrm{N}_{>3 \mathrm{~nm}}$ very well (Fig. $2 \mathrm{j}$ ). For 20 April and 19 May 1998, the simulated increase of $\mathrm{N}_{>3 \mathrm{~nm}}$ is earlier and steeper than the measured increase of $\mathrm{N}_{>3 \mathrm{~nm}}$ (Figs. 2k and 1). Although the simulations seem to reproduce the measured data for both spring data sets, the different structures of $\mathrm{N}_{>3 \mathrm{~nm}}$ indicate that for 19 May (Fig. 21) the simulated and observed maxima are out of phase. The simulated burst in $\mathrm{N}_{>3 \mathrm{~nm}}$ coincides with the steep increase in $\mathrm{H}_{2} \mathrm{SO}_{4 \text { (g) }}$ (Fig. 2h), whereas the observed burst in $\mathrm{N}_{>3} \mathrm{~nm}$ lags half an hour behind the simulated burst. For 20 April, the simulated increase in $\mathrm{N}_{>}$nm (Fig. $2 \mathrm{k}$ ) coincides with the small hump in RH at 10:00 (Fig. 2c) and the earlier increase in $\mathrm{H}_{2} \mathrm{SO}_{4}$ (g) (Fig. 2g), whereas the observed increase evolves over a longer time period coinciding with falling humidity.

To achieve agreement between measured and modelled particle number concentration, the nucleation rate was decreased for 26 January by a factor of 5 , and increased by $10^{4}$ for 26 December, $10^{13}$ for 20 April, and $10^{5}$ for 19 May.

After 1 to $2 \mathrm{~h}$ of simulated increasing particle number concentration, $\mathrm{N}_{>3 \mathrm{~nm}}$ decreases due to coagulation. On average, for all 12 cases, the simulated decrease in particle number concentration diverges about $20 \% 3 \mathrm{~h}$ after the maxima and about $40 \% 6 \mathrm{~h}$ after the maxima. We attribute these differences to neglected aerosol sinks associated with mixing, such as deposition.

The simulation results for particle surface area concentration are shown in Figs. 2m-p. For 26 December (Fig. 2m), 20 April (Fig. 2o), and 19 May (Fig. 2p), the model accurately reproduces the overall tendency, but the simulated particle surface area concentration is too low for 19 May. 26 January 2000 (Fig. 2n), shows large fluctuations and the measured and simulated results do not agree, probably because of the effect of advection and mixing of polluted air, which is not represented in the model. Unfortunately, trace-gas measurements are missing for the time period of 13:00-18:00. However, strongly increasing NO concentrations around noon and enhanced levels of $\mathrm{SO}_{2}$ and $\mathrm{NO}_{2}$ after 18:00 indicate the impact of polluted air. Any significant impact of $c f$ on discrepancies between measured and calculated particle surface area can be ruled out, because the $c f$ affects noticeably only the zero moment.

The evolution of simulated particle surface area concentra- 

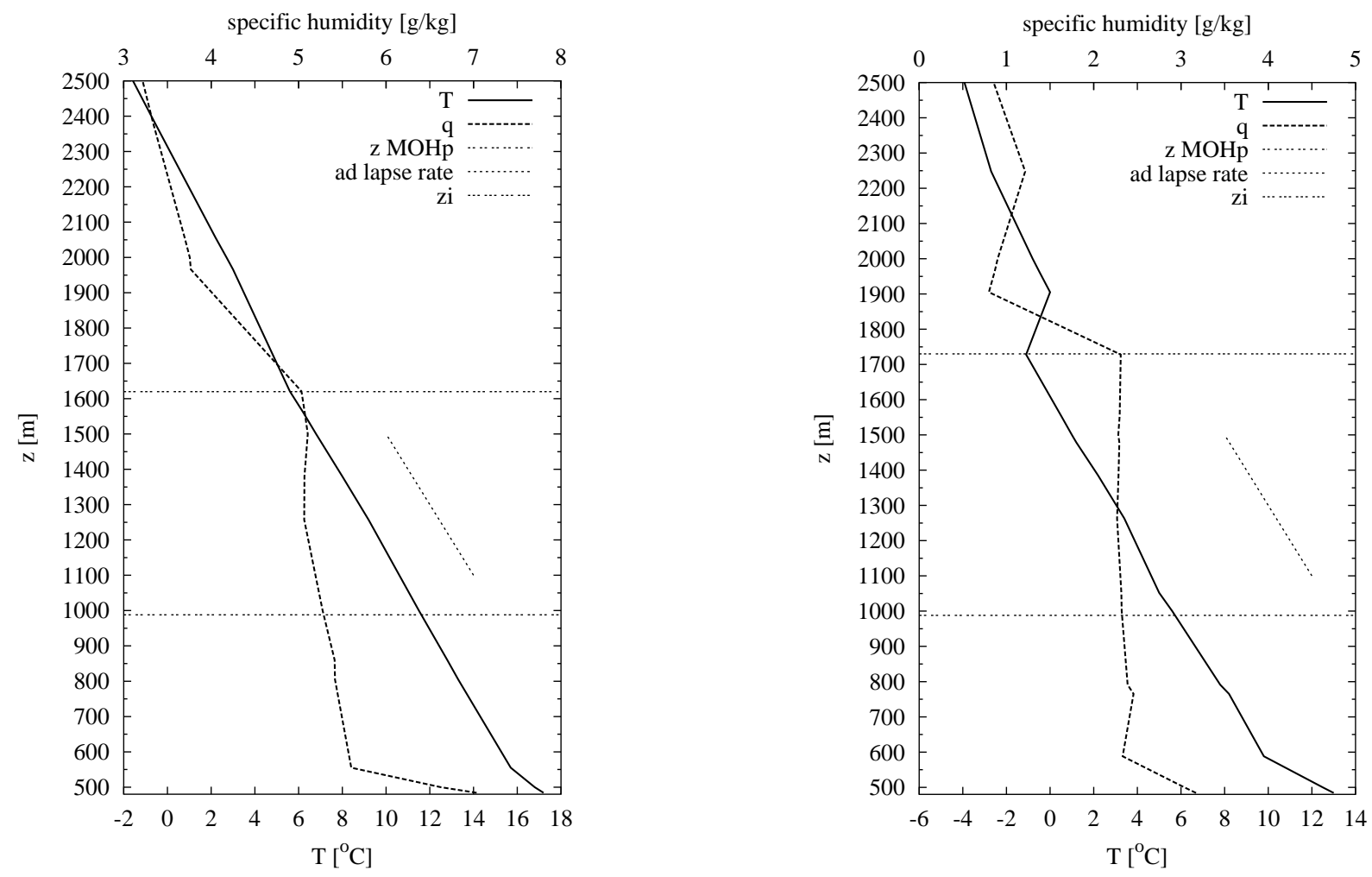

Fig. 4. Vertical profiles for specific humidity and temperature, Munich-Oberschleissheim, 19 May 1998 (left) and 20 April 1998 (right).

tion is smooth in all four cases. The measurements for particle surface area concentration show distinct fluctuations. The fluctuations in particle surface area can be caused by advection and mixing of either polluted or clean air.

\subsection{Micrometeorological influence on 20 April and 19 May 1998}

The simulations for 20 April 1998 and for 19 May 1998 are characterised by simulated $\mathrm{N}_{>3} \mathrm{~nm}$ profiles that are steeper than the measured profiles and where the simulated onset of increasing $\mathrm{N}_{>3 \mathrm{~nm}}$ occurs before the measured increase of $\mathrm{N}_{>3 \mathrm{~nm}}$. Dew-point temperature measurements taken at 1 min intervals were available for both days. As shown in Fig. 3 these data provide further indications of micrometeorological processes prior to the nucleation bursts. Both dew-point temperature time series show strong fluctuations. Strong vertical exchange processes can be inferred for both cases because for 19 May 1998 the wind speed was lower than $1 \mathrm{~m} / \mathrm{s}$ from 10:00 to 12:00 and for 20 April the wind speed was about $2 \mathrm{~m} / \mathrm{s}$ from 10:00 to 13:00. In both cases the main increase in observed $\mathrm{N}_{>3} \mathrm{~nm}$ was accompanied by a significant reduction in dew-point temperature. This might indicate that drier air from aloft was entrained into the boundary layer and mixed downwards by so-called topdown diffusion. Specific humidity taken from radiosonde profiles can be used as an indicator for vertical exchange if there is a significant difference between the surface layer and the entrainment layer. Unfortunately, the closest radiosonde station was located $70 \mathrm{~km}$ northeast of the site at MunichOberschleissheim. However, for 20 April and 19 May there were well-developed boundary layers several hundred meters higher than the MOHp site, and the existence of weak zonal flows allows us to rule out strong orographic effects, so that we can use the distant data $70 \mathrm{~km}$ away to interpret the measurements at the MOHp site. Figure 4 shows the temperature and specific humidity profiles taken at MunichOberschleissheim. The elevation of the MOHp site is indicated by the horizontal line at $988 \mathrm{~m}$. The temperature lapse rate was nearly adiabatic for both cases, indicating that wellmixed boundary layers developed, reaching up to $\approx 1600 \mathrm{~m}$ for 19 May and up to $\approx 1700 \mathrm{~m}$ for 20 April. Assuming horizontally homogeneous conditions and a shallow superadiabatic surface layer at the MOHp site, the temperature difference between the measurement site and the top of the boundary layer would have been between 7 and $8^{\circ} \mathrm{C}$.

The dew-point temperature time series for 19 May 1998 indicates that marked variations occurred at frequencies from 30 to $60 \mathrm{~min}$. These variations might indicate the existence of turbulent eddies and plumes. $\mathrm{H}_{2} \mathrm{SO}_{4}(\mathrm{~g})$ fluctuations seemed to correspond to fluctuations of dew-point temperatures. In 
Table 1. Measured parameters for the 12 data sets used in this work. The values were taken at the begin of increasing simulated $N_{>3 n}$

\begin{tabular}{cccccc}
\hline date & $\begin{array}{c}\partial \mathrm{T} / \partial \mathrm{z} \\
\mathrm{Km}^{-1}\end{array}$ & $\begin{array}{c}\mathrm{T}_{2 \mathrm{~m}} \\
\mathrm{~T} \mathrm{in}{ }^{\circ} \mathrm{C}\end{array}$ & $\begin{array}{c}\text { surface area } \\
\mathrm{nm}^{2} \mathrm{~cm}^{-3}\end{array}$ & $\begin{array}{c}\text { wind } \\
\text { direction }\end{array}$ & $\begin{array}{c}|\mathrm{U}| \\
\mathrm{ms}^{-1}\end{array}$ \\
\hline 010498 & -0.7 & 10.9 & $1.2 \mathrm{e} 8$ & $\mathrm{~W}$ & 8.3 \\
200498 & -2.8 & 6.1 & $2.3 \mathrm{e} 7$ & $\mathrm{SW}$ & 2.1 \\
150598 & -3.6 & 13.6 & $5.2 \mathrm{e} 7$ & ONO & 7.1 \\
160598 & -4.4 & 11.6 & $3.1 \mathrm{e} 7$ & NO & 6.2 \\
190598 & -2.5 & 10.7 & $3.6 \mathrm{e} 7$ & WSW & 0.4 \\
231298 & 1.7 & -3.0 & $1.3 \mathrm{e} 7$ & SSO & 2.7 \\
261298 & 0.3 & 4.1 & $6.0 \mathrm{e} 6$ & WSW & 5.3 \\
030199 & 0.5 & 2.2 & $7.0 \mathrm{e} 6$ & WSW & 10.0 \\
140499 & -2.5 & 6.0 & $6.3 \mathrm{e} 6$ & WSW & 6.0 \\
130100 & 0.6 & -3.9 & $5.0 \mathrm{e} 6$ & WSW & 5.5 \\
260100 & 1.0 & -7.9 & $1.4 \mathrm{e} 7$ & SW & 2.0 \\
270100 & 0.8 & -3.3 & $7.1 \mathrm{e} 6$ & WSW & 7.3 \\
\hline
\end{tabular}

contrast, the measured $N$ lagged about 1 to $1.5 \mathrm{~h}$ behind the measured $\mathrm{H}_{2} \mathrm{SO}_{4}(\mathrm{~g})$. For 20 April 1998, until 10:30 $\mathrm{H}_{2} \mathrm{SO}_{4}$ (g) fluctuations seemed to correspond to fluctuations of dew-point temperature. The time lag between $\mathrm{N}_{>3} \mathrm{~nm}$ and $\mathrm{H}_{2} \mathrm{SO}_{4}$ (g) was about $2 \mathrm{~h}$ in the morning, but thereafter it is difficult to associate $N$ to $\mathrm{H}_{2} \mathrm{SO}_{4}(\mathrm{~g})$. However, the variations in dew-point temperatures might indicate the existence of turbulent eddies and plumes that occurred at shorter cycles than the time-lag between $N$ and $\mathrm{H}_{2} \mathrm{SO}_{4}$ (g) .

These two spring data sets provide indications of the impact of vertical exchange processes on the differing model responses and of the complexity of interacting processes.

\subsection{Comparisons of measured and simulated results}

In the previous sections we compared aerosol dynamics simulations to four data sets that represent distinct atmospheric conditions. In this section we use regression analysis to compare simulation and measurement results for all 12 data sets, and discuss the origin of the nucleation-rate correction, $c f$, for all simulations. To assess the degree to which vertical exchange processes can explain the differences between the measured and simulated particle size distributions, the best available indicator of vertical exchange processes is the local temperature gradient. Temperature measurements were made at 0.05 and $2 \mathrm{~m}$. Due to the complex terrain in the vicinity of the measurements, calculating the temperature gradient from radiosonde data taken $70 \mathrm{~km}$ away may not represent local conditions. In particular, for winter days characterised by stable stratification, temperature profiles from Munich-Oberschleissheim do not represent the local conditions at MOHp. Because it is difficult to determine from measurements the time interval for the onset of particle for-

\section{cf versus $\mathrm{dT} / \mathrm{dz}$}

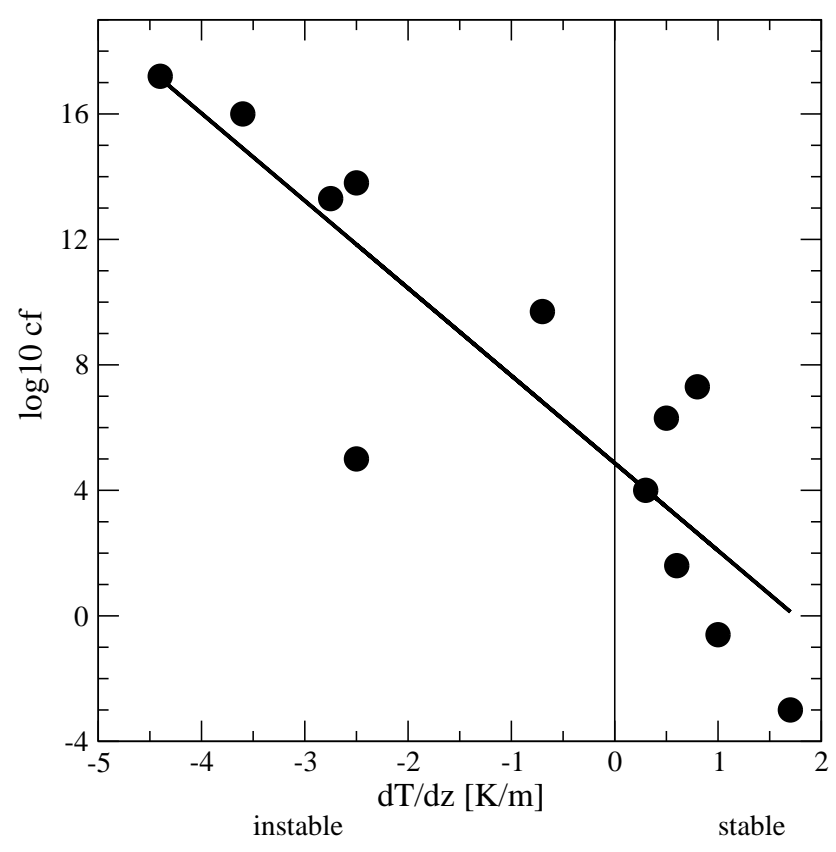

Fig. 5. $\log _{10}$ correction factor $(c f)$ versus $\partial \mathrm{T} / \partial \mathrm{z}$.

mation, the values for the near-surface temperature gradient, wind speed and direction, and particle surface area concentration were taken at the onset of the simulated increase of $\mathrm{N}_{>3 \mathrm{~nm}}$ and are shown in Table 1 .

For all 12 cases the gradient between the surface and ground temperatures was related to the logarithm of $c f$ as an indicator of the difference between measured and simulated results (Fig. 5). The logarithm of $c f$ varied from -3 to 17.2.

Figure 5 shows a distinct relation between $c f$ and the nearsurface temperature gradient. For the 12 cases we considered, a strong correlation was obtained. With increasing atmospheric instability (increasing negative temperature gradient) and related increased forcing of buoyancy-driven mixing processes, $c f$ increased. For neutral conditions and stable stratification (positive temperature gradient) $c f$ decreased with increasing atmospheric stability. In the stable regime the effect of shear-driven turbulence on atmospheric mixing decreases with increasing atmospheric stability. The interaction between wind shear and thermal stratification is described below.

For five out of six winter data sets, our box model reproduced the onset of increasing $\mathrm{N}_{>3} \mathrm{~nm}$ within a few minutes. In contrast, on average the spring data sets show about a 1-h premature onset of increasing $\mathrm{N}_{>3} \mathrm{~nm}$. This bias confirms that for convective conditions important time and length scales are omitted in the model, which strongly affect nucleation. 
cf versus buoyancy/windshear

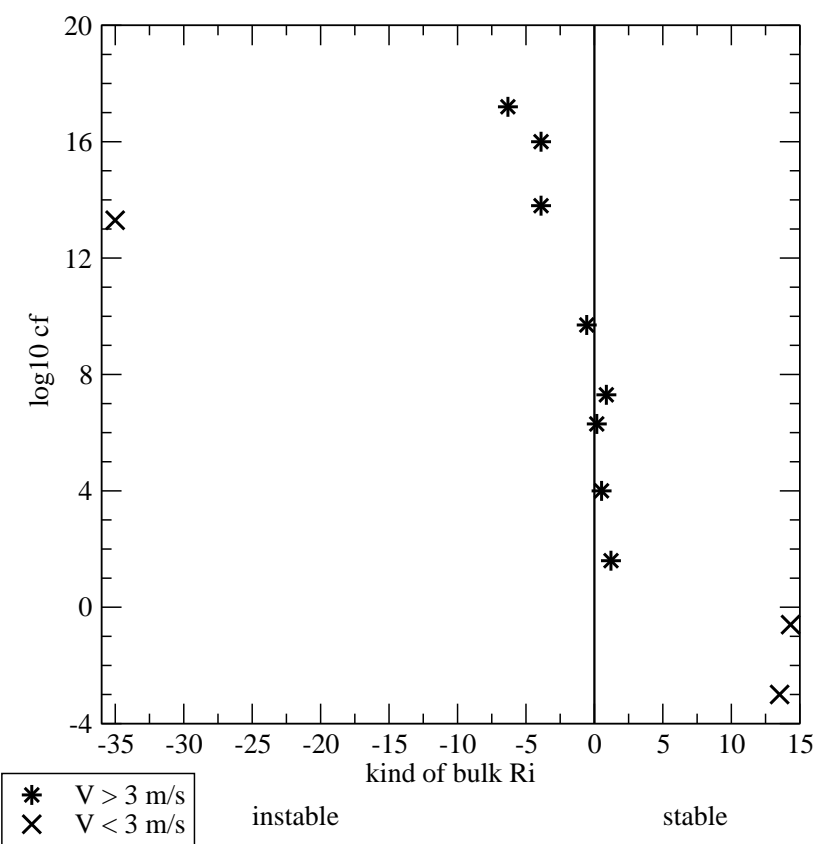

Fig. 6. Nucleation rate correction, $c f$, versus auxiliary bulk Richardson number, $\tilde{\mathrm{R}} \mathrm{i}_{\mathrm{B}}$. $\partial \mathrm{T} / \partial \mathrm{z}$ and $\partial \mathrm{U} / \partial \mathrm{z}$ are taken at different altitudes.

By analysing the atmospheric conditions that correspond to each of the data sets, the comparison between the measured and simulated evolution of $\mathrm{N}_{>3 \mathrm{~nm}}$ is the best for data sets corresponding to stable atmospheric conditions, and degrades for the data sets corresponding to progressively more unstable atmospheric conditions. For data sets corresponding to unstable atmospheric conditions, the simulated profile of $\mathrm{N}_{>3 \mathrm{~nm}}$ is typically too steep and the onset of the sharp increase of $\mathrm{N}_{>} 3 \mathrm{~nm}$ occurs too soon.

Wind shear is another important atmospheric mixing process that affects particle nucleation and could explain part of the difference between our measured and simulated results. In particular, for stable, stratified atmospheric conditions, vertical mixing is driven by wind shear. If wind speed is related to $c f$, this would indicate that wind shear strongly affects particle nucleation. However, no correlation between wind speed and $c f$ was found, which could mean that buoyancy-driven turbulence is the dominant process.

$\mathrm{Ri}$ relates the effect of buoyancy-driven turbulence to shear-driven turbulence. To calculate $\mathrm{Ri}_{\mathrm{B}}$, only two temperature measurements at different heights and one wind-speed measurement (with the boundary condition $U=0$ for $z=0$ ) are required. Although the wind-speed measurements should be made at the same height as the temperature measurements, at $\mathrm{MOHp}$ temperatures were only measured at 0.05 and $2 \mathrm{~m}$, and the wind speed $(U)$ was measured at $40 \mathrm{~m}$. We therefore cf versus particle surface area

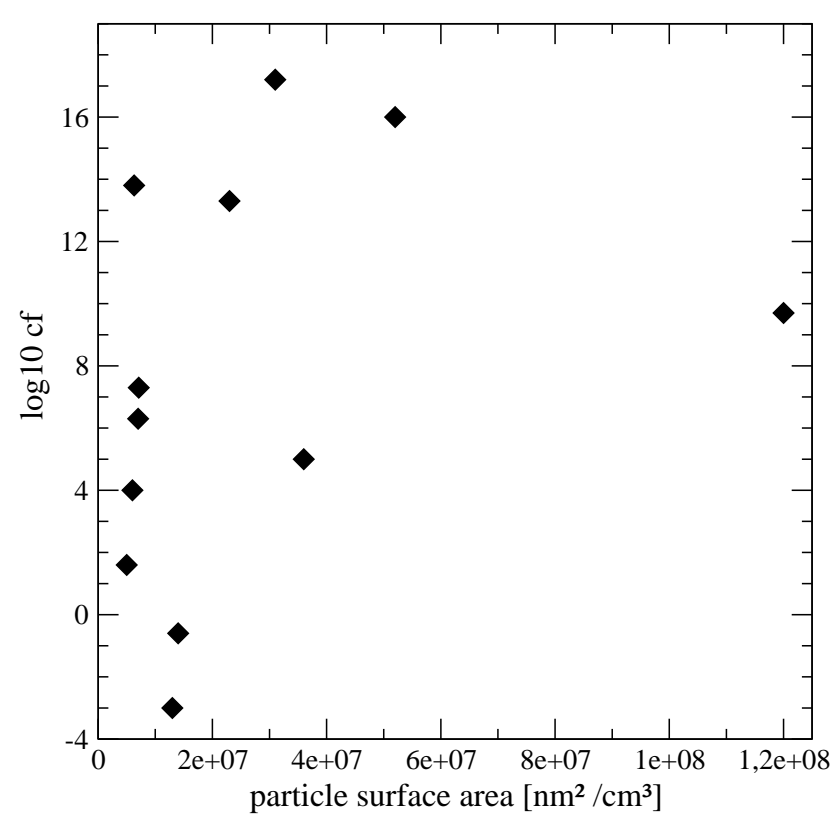

Fig. 7. Logarithm of nucleation rate correction, $\log _{10}(c f)$, versus particle surface area concentration.

calculated a bulk value for an auxiliary $\tilde{R} i_{B}$ as

$\tilde{R} i_{B}=\frac{g}{\theta} \frac{\triangle \theta / \triangle z_{1}}{\triangle U / \triangle z_{2}}$.

In Eq. (6) we set $\Delta z_{1}=2 \mathrm{~m}$ and $\Delta z_{2}=40 \mathrm{~m}$. The resulting values for $\tilde{R} i_{B}$ are shown in Fig. 6 .

The scatterplot shown in Fig. 6 indicates an inverse relation between $c f$ and $\tilde{\mathrm{R}}_{\mathrm{B}}$ for wind speeds higher than $3 \mathrm{~m} / \mathrm{s}$. For increasing $\tilde{\mathrm{R}} \mathrm{i}_{\mathrm{B}}$ (i.e. increasing atmospheric stability) $c f$ decreased (i.e. lower $c f$ ). These results may indicate that low wind speeds and stable atmospheric conditions produce large, positive $\tilde{\mathrm{R}} \mathrm{i}_{\mathrm{B}}$. In this regime wind shear is small and turbulence is suppressed by the stable atmospheric conditions, yielding laminar flow conditions. With increasing wind speed, and therefore increasing wind shear, laminar flow shifts to turbulent flow when Ri decreases to about 0.25 (Stull, 1988). Because we calculated the temperature gradient just for a height interval of $2 \mathrm{~m}$, the critical value for $\tilde{R} i_{B}$ should be greater than 0.25 . Two of the data sets that we considered may fall within this stable regime, and although four data sets had positive temperature gradients, which should yield thermally stable atmospheric conditions $\left(1.2>\tilde{\mathrm{R}} \mathrm{i}_{\mathrm{B}}>0.15\right.$ indicated by stars $)$, according to the criteria defined by Eq. (6), these four data sets are classified as unstable and may indicate some influence of wind shear in this regime. With decreasing $\tilde{R} i_{B}$, for $\left(\tilde{\mathrm{R}} \mathrm{i}_{\mathrm{B}}<0\right)$ buoyancy-driven turbulence dominates the turbulent exchange processes, so that there is only 1 data set that 
was noticeably affected by wind shear. There are also two data sets that are characterised by calm winds and strong negative $\partial \mathrm{T} / \partial \mathrm{z}$. For one of these data sets $c f=10^{5}$ and $R i=-853$, which lay outside the range of Fig. 6, and therefore are not shown. The results shown in the scatterplot in Fig. 6 indicate the complexity of interacting atmospheric processes and the different flow regimes under which the measurements were made.

Similar to the scatterplots shown in Fig. 5 and 6, Fig. 7 shows the relationship between $c f$ and particle surface area concentration. Figure 7 indicates a weak relation between $c f$ and particle surface area concentration. For entrainment of aerosol with low preexisting particle surface area concentration, subsequent mixing and dilution could yield only a weak signal in the time series measured at ground level.

Regression analysis confirmed that the evolution of particle number concentration was significantly affected by micrometeorological processes, such as strong convection on some days. The main problem with this analysis is that the atmospheric conditions affecting particle formation might have been very different from the atmospheric conditions at the point of measurements. We therefore look in the data sets for indicators of mixing from layers above the measurement points down into the layers where measurements were made. The near-surface temperature gradient and $\tilde{R} i_{B}$ were good indicators of the impact of atmospheric mixing on particle nucleation. Near the top of the boundary layer the temperature, specific humidity, and particle size distributions might be substantially different from those closer to the ground, and could favour enhanced particle formation rates. Even for stable atmospheric conditions, strong atmospheric inversions below the site could also increase particle formation rates. Particles may form at the discontinuity under the inversion, below the MOHp, and could be transported upwards by wind shear and by orographic lift.

\subsection{Particle growth}

The average of the difference between the measured and simulated particle surface area concentration was calculated for all 12 cases by integrating the difference between the measured and simulated particle surface area concentration over the six-hour measurement period, beginning with the simulated increase of particle number concentration. Similar to Fig. 5, Fig. 8 shows 6-h mean differences for particle surface area concentrations. The differences shown in Fig. 8 are normalized by the measured particle surface area concentration. We define this normalized difference between the measured and simulated particle surface area concentration as $\Delta S$.

For particle nucleation, $c f$ was used to determine the difference between particle nucleation and the evolution of particle number concentration, and could be correlated to the vertical exchange rate. However, for the behaviour of the particle surface area concentration, there is no identifiable relation between $\triangle S$ and the vertical exchange processes. This
Integrated rel. differences for $\mathrm{S}$ versus $\mathrm{dT} / \mathrm{dz}$

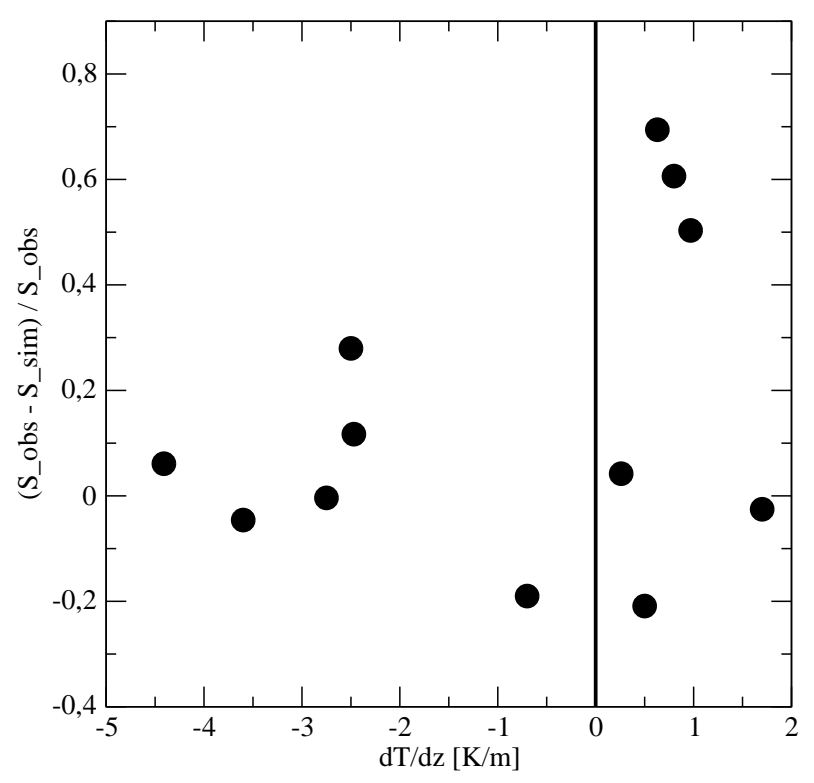

Fig. 8. Six-hour mean difference of the measured and simulated particle surface area concentration normalized by the measured particle surface area concentration, versus $\partial \mathrm{T} / \partial \mathrm{z}$.

suggests that particle nucleation and growth are controlled by different processes. The processes most likely controlling $\triangle S$ are:

- Advection of polluted air

- Condensation and evaporation of unidentified species. Likely species are ammonia, nitric acid $\left(\mathrm{HNO}_{3}\right)$, oxygenated biogenic hydrocarbons, and other unidentified, condensible, organic species

Because these processes may occur simultaneously, it is difficult to determine their relative contributions to $\triangle S$.

Hourly $\mathrm{NO}_{2}$ and $\mathrm{NO}$ measurements were available for ten out of the twelve selected cases for the periods of interest. We used $\mathrm{NO}_{\mathrm{x}}$ measurements as an indicator for the degree of pollution of the air.

The data sets for measured particle surface area concentration for 20 April (Fig. 2o), 19 May (Fig. 2p), and 26 December 1998 (Fig. 2m) show low values of $\triangle S$, and were characterised by relatively low $\mathrm{NO}_{\mathrm{x}}$ concentrations, ranging from 0.5 to 2 ppbv. For 26 January $2000 \mathrm{NO}_{\mathrm{x}}$ measurements are missing for the period of the most interest (see Fig. 9). However the remaining measurements for the late evening indicate high $\mathrm{NO}_{\mathrm{x}}$ levels.

Two other data sets with large $\Delta S$ are also shown in Fig. 9. For both cases enhanced $\mathrm{NO}_{\mathrm{x}}$ concentrations and enhanced particle surface area concentrations were measured. Moreover, the time series for $\mathrm{NO}_{\mathrm{x}}$ indicates a time evolution similar to the time series for measured particle surface area 

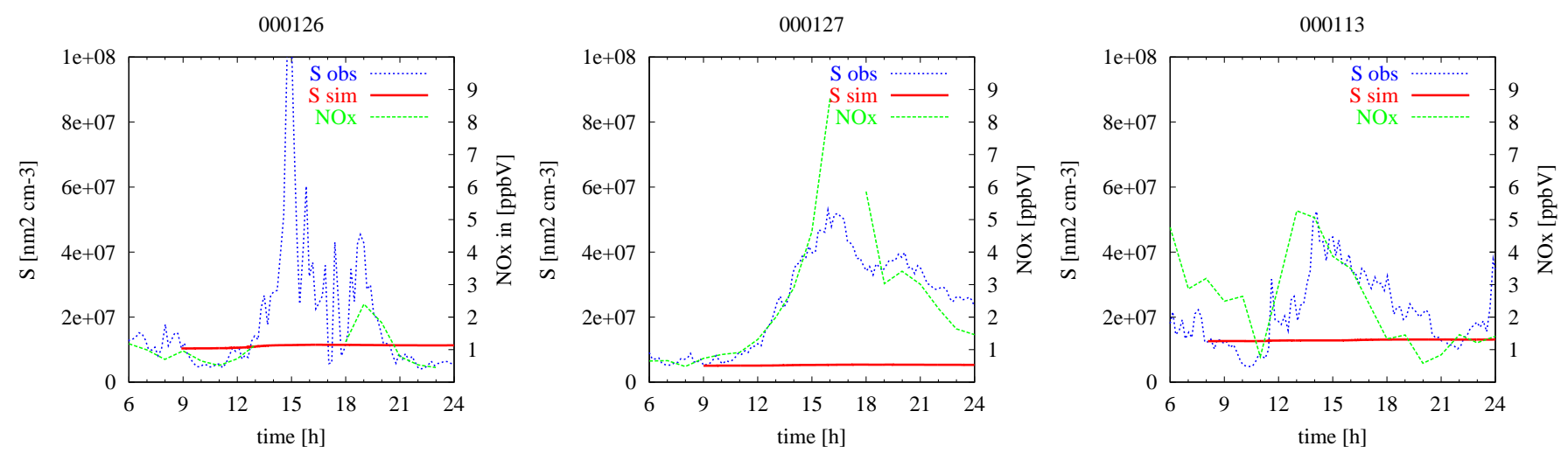

Fig. 9. Particle surface area and $\mathrm{NO}_{\mathrm{x}}$ concentration for the three data sets with the highest difference between measured and simulated surface area concentration, $\triangle S$.

concentration. Using $\mathrm{NO}_{\mathrm{x}}$ as an indicator of combustion sources, this suggests that the site was affected by emissions, most likely from nearby roads and heating sources below the Hohenpeissenberg measurement site.

\section{Conclusions}

Selected data sets from a long-term set of atmospheric field measurements of particle size distributions, sulphuric acid concentrations, and meteorological parameters were used for comparisons with box model simulations of atmospheric particle nucleation and growth. The primary objective of this work was to study differences between the measured and simulated particle size distributions, and to identify atmospheric processes responsible for these differences. The differences for particle number concentration were evaluated by determining for each case a correction factor for the nucleation rate expression, which was the only free parameter in the model. The benefit of the chosen approach was that we are able to compare a closed set of measurements against model results, and assumptions related to boundary conditions, background concentrations, particle composition, etc. were avoided.

Our results indicate that the measured and simulated particle number concentration compared well for data sets where the atmosphere was stably stratified and when the wind speed was relatively low. For wind speeds greater than $6 \mathrm{~m} / \mathrm{s}$ and for stable stratification, the comparison degrades. Larger differences in particle number concentration were found for days with convective conditions, as indicated by negative near-surface temperature gradients and radiosonde profiles. For particle number concentration profiles where the simulated particle number concentration either rose faster than the measured increase, or where the onset of a sharp rise in particle number concentration occurred before the measured onset, the cause could be related to buoyancy-driven turbu- lent exchange processes. This indicates that under convective conditions the initial particle nucleation process occurs higher up in the atmosphere, where more favourable conditions occur followed by downward mixing and growth to detectable sizes. Therefore, a significant part of these differences and their variability is attributed to non-local formation of particles and micrometeorological processes that cause them to be transported to the ground-based measurement site. Our results suggest that buoyancy-driven turbulence and wind shear are the micrometeorological processes accounting for such transport.

In contrast to particle formation, micrometeorological processes are not sufficient to explain the differences in simulated particle surface area concentration. This indicates that particle surface area concentration is affected by condensation and evaporation processes of additional species, which are strongly affected by transport of emissions, such as $\mathrm{NO}_{\mathrm{x}}$.

Our comparison of measured and simulated particle size distribution parameters indicate the complexity of various interacting processes, such as micrometeorology, particle nucleation, growth, coagulation, transport, and deposition. To gain further insight into these processes, measurements of, e.g. vertical profiles of quantities characterizing turbulent transport processes up to the entrainment layer and $\mathrm{NH}_{3}$ concentrations are desirable.

Acknowledgements. This work was performed in the framework of the Ford University Research Program and the German Aerosol Research Program (AFS). The experiments were funded by the Bundesministerium für Bildung und Forschung (BMBF) project 07AF201A,B. We thank O. Hellmuth, A. Wiedensohler for helpful discussions and $\mathrm{S}$. Gilge for providing the $\mathrm{NO}_{\mathrm{x}}$ data. We thank the two anonymous referees for their constructive comments. 


\section{References}

Berresheim, H., Elste, T., Plass-Dülmer, C., Eiselse, F. L., and Tannner, D. J.: Chemical ionization mass spectrometer long-term measurements of atmospheric $\mathrm{OH}$ and $\mathrm{H}_{2} \mathrm{SO}_{4}$, Int. J. Mass Spectrom., 202, 91-109, 2000.

Bigg, E. K.: A mechanism for the formation of new particles in the atmosphere, Atm. Res., 43, 129-137, 1997.

Birmili, W. and Wiedensohler, A.: New particle formation in the continental boundary layer: Meteorological and gas phase parameter influence, Geophys. Res. Lett., 27, 3325-3328, 2000.

Birmili, W., Wiedensohler, A., Plass-Dülmer, C., and Berresheim, $\mathrm{H}$.: Evolution of newly formed aerosol particles in the continental boundary layer: A case study including $\mathrm{OH}$ and $\mathrm{H}_{2} \mathrm{SO}_{4}$ measurements, Geophys. Res. Lett., 27, 2205-2209, 2000.

Birmili, W., Wiedensohler, A., Heintzenberg, J., and Lehmann, K.: Atmospheric particle number size distribution in central Europe: Statistical relations to air masses and meteorology, J. Geophys. Res., 106, 32 005-32 018, 2001.

Birmili, W., Berresheim, H., Plass-Dülmer, C., Elste, T., Gilge, S., Wiedensohler, A., and Uhrner, U.: The Hohenpeisseenberg aerosol formation experiment (HAFEX): a long-term study including size-resolved aerosol and $\mathrm{H}_{2} \mathrm{SO}_{4}, \mathrm{OH}$ and terpene measurements, Atmos. Chem. Phys., in press, 2003.

Charlson, R. J. and Heintzenberg, J. (Eds): Aerosol Forcing of Climate, John Wiley \& Sons, Chichester, 1995.

Coffmann, D. J. and Hegg, D. A.: A preliminary study of the effect of ammonia on particle nucleation in the marine boundary layer, J. Geophys. Res., 100, 7147-7160, 1995.

Dockery, D. W. and Pope C. A., Acute respiratory effects of particulate air pollution, Annual Review of Public Health, 15, 107-132, 1994.

Easter, R. C. and Peters, L. K.: Binary homogeneous nucleation: Temperature and relative humidity fluctuations, nonlinearity, and aspects of new particle formation in the atmosphere, J. Appl. Met., 33, 775-784, 1994.

Fricke, W., Kaminski, U., and Gilge, S.: Der Hohenpeissenberg im GAW-Programm der WMO, promet, 26. Jahrgang, Heft 1/2, 5360, 1997.

Jaecker-Voirol, A., Mirabel, P., and Reiss, H.: Hydrates in supersaturated binary sulfuric acid-water vapor: A reexamination, J. Chem. Phys., 87, 4849-4852, 1987

Jaenisch, V., Stratmann, F., and Wilck, M.: Particle nucleation and condensational growth during turbulent mixing processes, J. Aerosol Sci., 29, 1161-1162, 1998

Korhonen, P., Kulmala, M., Laaksonen, A., Viisanen, Y., McGraw, R., and Seinfeld, J. H.: Ternary nucleation of $\mathrm{H}_{2} \mathrm{SO}_{4}, \mathrm{NH}_{3}$, and $\mathrm{H}_{2} \mathrm{O}$ in the atmosphere, J. Geophys. Res., 104, 26349-26353, 1999.

Kulmala, M., Laaksonen, A., and Pirjola, L., Parametrisations for sulfuric acid / water nucleation rates, J. Geophys. Res., 103, 8391-8307, 1998.

Kulmala, M., Pirjola, L., and Mäkelä, J. M.: Stable sulphate clusters as a source of new atmospheric particles, Nature, 404, 66-69, 2000.

Mäkelä, J. M., Aalto, P. P., Jokinen, V., Pohja, T., Nissinen, A.,
Palmroth, S., Markkanen, T., Seitsonen, K., Lihavainen, H., and Kulmala, M.: Observations of ultrafine aerosol particle formation and growth in boreal forest, Geophys. Res. Lett., 24, 1219 1222, 1997.

McMurry, P. H., Woo, K. S., Weber, R. J., Chen, D.-R., and Pui, D. Y. H.: Size distributions of $3-10 \mathrm{~nm}$ atmospheric particles: implications for nucleation mechanisms, Phil. Trans. Royal Soc., A358, 2625-2642, 2000.

Nilsson, E. D. and Kulmala, M.: The potential for atmospheric mixing processes to enhance the binary nucleation rate, J. Geophys. Res., 103, 1381-1389, 1998.

Nilsson, E. D., Pirjola, L., and Kulmala, M.: The effect of atmospheric waves on aerosol nucleation and size distribution, J. Geophys. Res., 105, 19917-19926, 2000.

O’Dowd, C. D., McFiggens, G., Pirjola, L., Creasey, D. J., Hoell, C., Smith, M. H., Allen, B., Plane, J. M. C., Heard, D. E., Lee, J. D., Pilling, M. J., and Kulmala, M.: On the photochemical production of new particles in the coastal boundary layer, Geophys. Res. Lett., 26, 1707-1710, 1999.

O’Dowd, C. D., Hämeri, K., Mäkelä, J. M., Väkeva, M., Aalto, P. P., de Leeuw, G., Kunz, G. J., Becker, E., Hansson, H.-C., Allen, A., G., Harrion, R. M., Berresheim, H., Kleefeld, C., Geever, M., Jennings, S. G., and Kulmala, M.: Coastal new particle formation: Environmental conditions and aerosol physicochemical characteristics during nucleation bursts, J. Geophys. Res., in press, 2002.

Pirjola, L., Kulmala, M., Wilck, M., Bischoff, A., Stratmann, F., and Otto, E.: Formation of sulphuric acid aerosols and cloud condensation nuclei: an expression for significant nucleation and model comparison, J. Aerosol Sci., 30, 1079-1094, 1999.

Stull, R. B.: An Introduction to Boundary Layer Meteorology, Kluwer Acad. Publishers, Norwell, Mass., 1988.

Weber, R. J., Marti, J. J., McMurry, P. H., Eisele, F. L., Tanner, D. J., and Jefferson, A.: Measurements of new particle formation and ultrafine particle growth rates at a clean continental site, J. Geophys. Res., 102, 4375-4385, 1997.

Weber, R. J., McMurry, P. H., Mauldin, R. L., Tanner, D. J., Eisele, F. L., Brechtel, F., Kreidenweis, S., Kok, G., Schillawski, R., and Baumgardner, D.: A study of new particle formation and growth involving biogenic gas species measured during ACE 1, J. Geophys. Res., 103, 16385-16396, 1998.

Weber, R. J., McMurry, P. H., Mauldin, R. L., Tanner, D. J., Eisele, F. L., Clarke, A. D., and Kapustin, V. N.: New particle formation in the remote troposphere: A comparison of observations at various sites, Geophys. Res. Lett., 26, 307-310, 1999.

Whitby, E. R. and McMurry, P. H.: Modal aerosol dynamics modeling, Aerosol Sci. Technol., 27, 673-688, 1997.

Wilck, M. and Stratmann, F.: A 2-D multicomponent modal aerosol model and its application to laminar flow reactors, J. Aerosol Sci., 28, 959-972, 1997.

Wilck, M.: Modal modelling of multicomponent aerosols, Dissertation, Universität Leipzig, 1998.

Wilemski, G.: Composition of the critical nucleus in multicomponent vapour nucleation, J. Chem. Phys., 80, 1370-1372, 1984.

Yu, F. and Turco, R. P.: Ultrafine aerosol formation via ionmediated nucleation, J. Geophys. Res., 27, 883-886, 2000. 